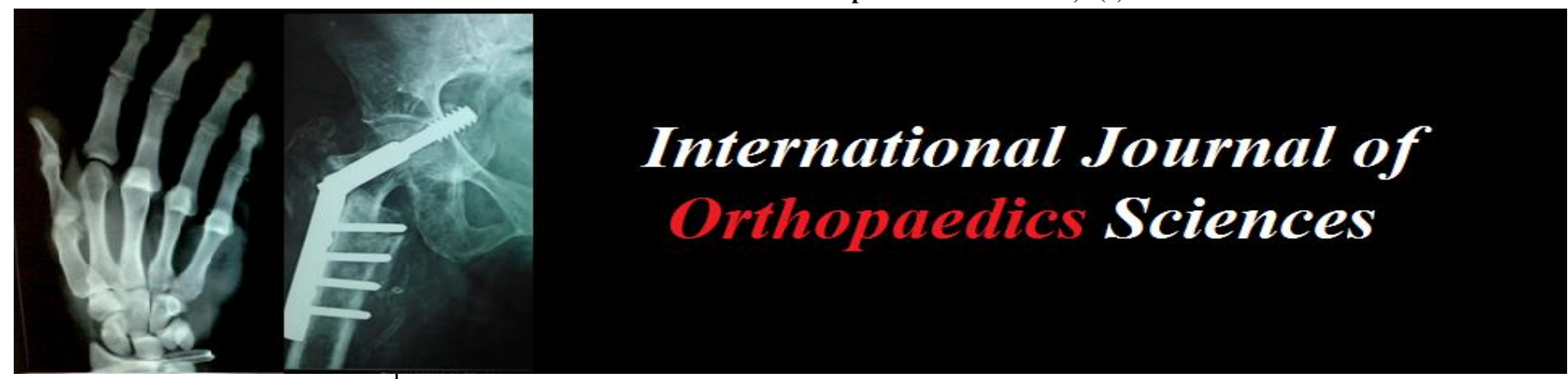

E-ISSN: 2395-1958

P-ISSN: 2706-6630

IJOS 2020; 6(3): 64-72

(C) $2020 \mathrm{IJOS}$

www.orthopaper.com

Received: 08-05-2020

Accepted: 10-06-2020

Dr. Abhishek Varshney Senior Resident, Department of Orthopaedics, ESIC Medical College, Faridabad, Haryana, India

Dr. Varun Garg

Senior Resident, Department of Orthopaedics, AIIMS, Rishikesh, Uttarakhand, India

Dr. Shailendra Srivastava Consultant Department of Orthopaedics, Santokba Durlabhji Memorial Hospital, Jaipur, Rajasthan, India

Dr. Sriram Sundararajan Senior Resident, Department of Orthopaedics, GMERS, Gotri Medical College, Vadodara, Gujarat, India
Corresponding Author: Dr. Varun Garg Senior Resident, Department of Orthopaedics, AIIMS, Rishikesh, Uttarakhand, India

\section{Percutaneous fixation with Kirschner wires versus volar locking plate fixation in adults for displaced intra articular fracture of distal radius}

\author{
Dr. Abhishek Varshney, Dr. Varun Garg, Dr. Shailendra Srivastava and \\ Dr. Sriram Sundararajan
}

DOI: https://doi.org/10.22271/ortho.2020.v6.i3b.2179

\section{Abstract}

Background: The present study was conducted to compare and contrast Kirschner wire fixation versus volar locking compression plating in the treatment of distal end radius fracture.

Materials \& Methods: The present study was conducted on patients of intraarticular distal radius fractures. Patients were divided into two groups, K-wire group and Volar plating group. Grading as per DASH score was used. Score $<25$ was excellent, 26-35 was good, 36-45 was moderate and $>45$ was poor.

Results: Fall from height was mode of injury in $36.67 \%$, fall on supinated hand was mode of injury in $13.33 \%$ and road traffic accident was mode of injury in $50 \%$ in $\mathrm{k}$ wire group. Fall from height was mode of injury in $3.33 \%$, fall on supinated hand was mode of injury in $30 \%$ and road traffic accident was mode of injury in $66.67 \%$ in volar plate group. Out of 30 patients in k wire group- 14 were type III, 4 were type IV, 9 were type VII, 3 were type VIII. Out of 30 patients in volar plate group-7 were type III, 2 were type IV, 14 were type VII, 7 were type VIII. 3 patients had NSWP, 6 Patient had SI, 2 Patient had WS, 2 patients had USP in volar plate group. 4 Patient had MKW, 4 patients had NSWP, 2 patients had USP, 3 patients had SI, 3 patients had WS, in k wire group.

Conclusion: Open reduction and internal fixation with a volar locking plate and closed reduction with percutaneous Kirschner wire fixation provide comparable excellent clinical and radiographic results in patients with distal radial fractures.

Keywords: Kirschner wire fixation, distal radial fractures, volar locking plate

\section{Introduction}

Distal forearm fractures have been treated in several ways since antiquity. The ancient Egyptians used immobilisation with wood splints and cloth, and the ancient Greeks, according to Hippocrates, immobilised the fractures for 20 days with linen rolls ${ }^{[1]}$.

The fracture pattern shows a bimodal age distribution with peaks in early adolescence and again in older age, it is characteristically seen with an increasing incidence with increasing age. Females have an eight fold increased lifetime risk of sustaining a fracture compared to males, and the lifetime risk of sustaining a distal radius fracture in Northern Europe is estimated to $15-16 \%$ for women and $2-3 \%$ for men Furthermore there is a seasonal variation with a higher incidence in the winter with snow, and also a higher incidence in areas with a high prevalence of osteoporosis ${ }^{[2]}$.

Treatment methods vary from immobilisation, external fixation and internal fixation, with increasing focus on obtaining perfect radiology and early mobilisation ${ }^{[3]}$. The fracture of the distal radius typically happens because of a fall on an outstretched hand. It occurs in the metaphysis of the distal radius within $2 \mathrm{~cm}$ of the distal end of the radius, is usually dorsally displaced and angulated, and can be accompanied by a fracture of the ulnar styloid ${ }^{[4]}$.

Percutaneous pinning is an effective method for certain fractures of the distal radius. Bridging external fixation uses a method of stable fixation proximal and distal to the fracture [5]. Another variant of external fixation is non-bridging external fixation, which is used to directly fixate the distal and proximal fragments together. ${ }^{6}$ The present study was conducted to compare and contrast Kirschner wire fixation versus volar locking compression plating in the treatment of distal end radius fracture. 


\section{Materials \& Methods}

The present interventional study (RCT) longitudinal study was conducted on patients of intraarticular distal radius fractures attending orthopaedic OPD to Santokba Durlab Ji Memorial Hospital Jaipur following inclusion criteria. The patients included in this study are of either sex and age $>18$ years, fracture presenting within one week and Frykman's types type III, IV, VII, VIII. Exclusion criteria were age less than 18 year, open fracture, any other fracture of ipsilateral upper limb, any pre-existing deformity, leading to functional compromise of wrist and hand. Patient with significant neurovascular deficit in the affected limb (Pathological fracture of distal radius). Sample size was calculated at $80 \%$ study power and alpha error of 0.005assuming standard deviation of 20 in DASH score at 12 weeks as per result of reference study.

Grading as per DASH score was used. Score $<25$ was excellent, 26-35 was good, 36-45 was moderate and >45 was poor. At the minimum detectable difference of 15 in DASH score, 29 patients of distal end radius are required in each group as sample size. It is further enhanced to 35 patients in each group as final sample size expecting $20 \%$ drops out/Lost to follow up/Attrition. Patients were divided into two groups, K-wire group and Volar plating group.

All patients were evaluated with detailed history including the mode of trauma, and associated injury if any and treatment received for the same. Clinical examination for deformity, pain, tenderness, swelling, distal neurovascular status was done. A thorough clinical examination for any associated injuries and medical problems to rule out any systemic illness was carried out simultaneously. After routine blood work-up, plain x-ray antero-posterior and lateral views were taken and fractures were classified as per Frykman classification of fractures for distal end radius. After pre-anaesthetic check-up and anaesthesia fitness, the patient was planned for surgery at the earliest. The affected limb was placed in a below elbow plaster of paris (P.O.P.) dorsal splint. Active finger movement and limb elevation was advised to prevent or decrease swelling of wrist and hand, Anti inflammatory and analgesics be administered for pain and swelling. All the patients were evaluated with $\mathrm{x}$-rays in two views ie Anteroposterior [A.P] and lateral views.

\section{Operative technique $-\mathrm{K}$ wire}

The patient was placed supine on the operation table. No tourniquet was used. Intravenous antibiotics in the form of 1 $\mathrm{gm}$ of ceftriaxone were administered before the start of the procedure. The arm, Forearm, hand was scrubbed with betadine scrub and was painted with betadine and spirit and then draped. The limb was placed on side board [Hard].Then two or multiple $\mathrm{k}$ wires inserted from radial side. Quality of reduction and fixation of fracture were checked by radiography after surgery. $\mathrm{K}$ wire bent nd dressing done. Below elbow slab applied Immediate post-operative check Xrays were taken in both AP and lateral views. $\mathrm{K}$ wire was removed at 6 weeks. Exercises of fingers, elbow and shoulder of the was started from day 1 post-op. Patients were made to start range of motion exercises at the wrist, in addition to the other exercises, at 6 weeks post-op after plaster removal. The patient was reviewed clinically and radiologically every 2 weekly for a month, then at 6 week, 12 week to assess the functional outcome. At every follow-up, DASH scoring system along with radiological assessment was performed in every patient and at 12 week follow-up, final assessment and evaluation was done.

\section{Operative technique - Locking compression plate}

The patient was placed supine on the operation table. No tourniquet was used. Intravenous antibiotics in the form of 1 $\mathrm{gm}$ of ceftriaxone were administered before the start of the procedure. The arm, Forearm, hand was scrubbed with betadine scrub and was painted with betadine and spirit and then draped. The limb was placed on side board [Hard]. A Henry incision in the distal forearm was selected, and then the skin was incised along the flexor carpi radialis muscle tendon and radial artery. The radial artery was protected and retracted to the radial side and the flexor carpi radialis muscle tendon and median nerve was retracted to the ulnar side. The quadrate pronator muscle was exposed. The pronator quadratus was detached from the radial side, to provide good exposure for anatomic reduction of the palmar cortex of the distal radius and for placement of the plate. After radial height, volar tilt angle and articular surface were corrected, the fracture reduction was maintained by temporary Kirschner wire fixation.

The LCP placed in position, locking sleeve is used to drill both the cortices. Locking screws are placed and the correct reduction is confirmed with $\mathrm{C}$-arm.

A thorough wash underlying structures sutured in layers followed by skin closure and betadine dressing done. The forearm is immobilised in a below elbow slab. Data was entered in Microsoft Excel Sheet to prepare master chart and were subjected for statistical analysis. Unpaired $\mathrm{T}$ test and repeated measure Anova test was used for the analysis.

\section{Post-operative care and rehabilitation}

Immediate Post-operative check $\mathrm{x}$-rays were taken both AP and lateral views. Active exercises of all the fingers, elbow and shoulder were carried out. Below elbow slab applied. Sutuers were removed at 15 Post-operative day. the patient were reviewed clinically and radiologically every 2 weekly for a month, then at 6 week 12 week to assess the functional outcome. At every follow-up, DASH scoring system along with radiologically assessment were performed in every patient and at 12 week follow-up, final assessment and evaluation done. The cumulated data then statistically analysed to conclude the final result of the study.

\section{Results}

Table 1: Distribution of case according to age

\begin{tabular}{|c|c|c|c|c|c|c|}
\hline \multirow{2}{*}{ Sex } & \multicolumn{2}{|c|}{ K-wire } & \multicolumn{2}{c|}{ Volar plating } & \multicolumn{2}{c|}{ Total } \\
\cline { 2 - 7 } & No. & $\boldsymbol{\%}$ & No. & $\boldsymbol{\%}$ & No. & $\%$ \\
\hline Male & 15 & 50.00 & 21 & 70.00 & 36 & 60.00 \\
\hline Female & 15 & 50.00 & 9 & 30.00 & 24 & 40.00 \\
\hline Total & 30 & 100.00 & 30 & 100.00 & 60 & 100.00 \\
\hline
\end{tabular}

Table I shows that male predominated with incidence of $70 \%$ of total number of patient while female constituted only $30 \%$ in volar plate group. Male and female were equal in proportion i.e. $50 \%$ in each group.

Table 2: Distribution of case according to Mechanism of injury

\begin{tabular}{|c|c|c|c|c|c|c|}
\hline \multirow{2}{*}{ MOI } & \multicolumn{2}{|c|}{ K-wire } & \multicolumn{2}{c|}{ Volar plating } & \multicolumn{2}{c|}{ Total } \\
\cline { 2 - 7 } & No. & $\boldsymbol{\%}$ & No. & \% & No. & \% \\
\hline FFH & 11 & 36.67 & 1 & 3.33 & 12 & 20.00 \\
\hline FOSH & 4 & 13.33 & 9 & 30.00 & 13 & 21.67 \\
\hline RTA & 15 & 50.00 & 20 & 66.67 & 35 & 58.33 \\
\hline Total & 30 & 100.00 & 30 & 100.00 & 60 & 100.00 \\
\hline
\end{tabular}


Table II shows that fall from height was mode of injury in $36.67 \%$, fall on supinated hand was mode of injury in $13.33 \%$ and road traffic accident was mode of injury in $50 \%$ in $\mathrm{k}$ wire group. Fall from height was mode of injury in $3.33 \%$, fall on supinated hand was mode of injury in $30 \%$ and road traffic accident was mode of injury in $66.67 \%$ in volar plate group.

Table 3: Distribution of case according to Frykmann Type

\begin{tabular}{|c|c|c|c|c|c|c|}
\hline \multirow{2}{*}{ Frykman Type } & \multicolumn{2}{|c|}{ K-wire } & \multicolumn{2}{c|}{ Volar plating } & \multicolumn{2}{c|}{ Total } \\
\cline { 2 - 7 } & No. & $\mathbf{\%}$ & No. & $\mathbf{\%}$ & No. & \% \\
\hline III & 14 & 46.67 & 7 & 23.33 & 21 & 35.00 \\
\hline IV & 4 & 13.33 & 2 & 6.67 & 6 & 10.00 \\
\hline VII & 9 & 30.00 & 14 & 46.67 & 23 & 38.33 \\
\hline VIII & 3 & 10.00 & 7 & 23.33 & 10 & 16.67 \\
\hline Total & 30 & 100.00 & 30 & 100.00 & 60 & 100.00 \\
\hline
\end{tabular}

Table III shows that out of 30 patients in $\mathrm{k}$ wire group- 14 were type III, 4 were type IV, 9 were type VII, 3 were type VIII. Out of 30 patients in volar plate group-7 were type III, 2 were type IV, 14 were type VII, 7 were type VIII.

Table 4: Distribution of case according to laterality

\begin{tabular}{|c|c|c|c|c|c|c|}
\hline \multirow{2}{*}{ Extremity } & \multicolumn{2}{|c|}{ K-wire } & \multicolumn{2}{c|}{ Volar plating } & \multicolumn{2}{c|}{ Total } \\
\cline { 2 - 7 } & No. & \% & No. & \% & No. & \% \\
\hline Left & 18 & 60.00 & 14 & 46.67 & 32 & 53.33 \\
\hline Right & 12 & 40.00 & 16 & 53.33 & 28 & 46.67 \\
\hline Total & 30 & 100.00 & 30 & 100.00 & 60 & 100.00 \\
\hline
\end{tabular}

Table IV shows that $40 \%$ had injury on right side and $60 \%$ had injury on left side in k wire group. $53.33 \%$ had injury on right side and $46.67 \%$ had injury on left side in volar plate group.

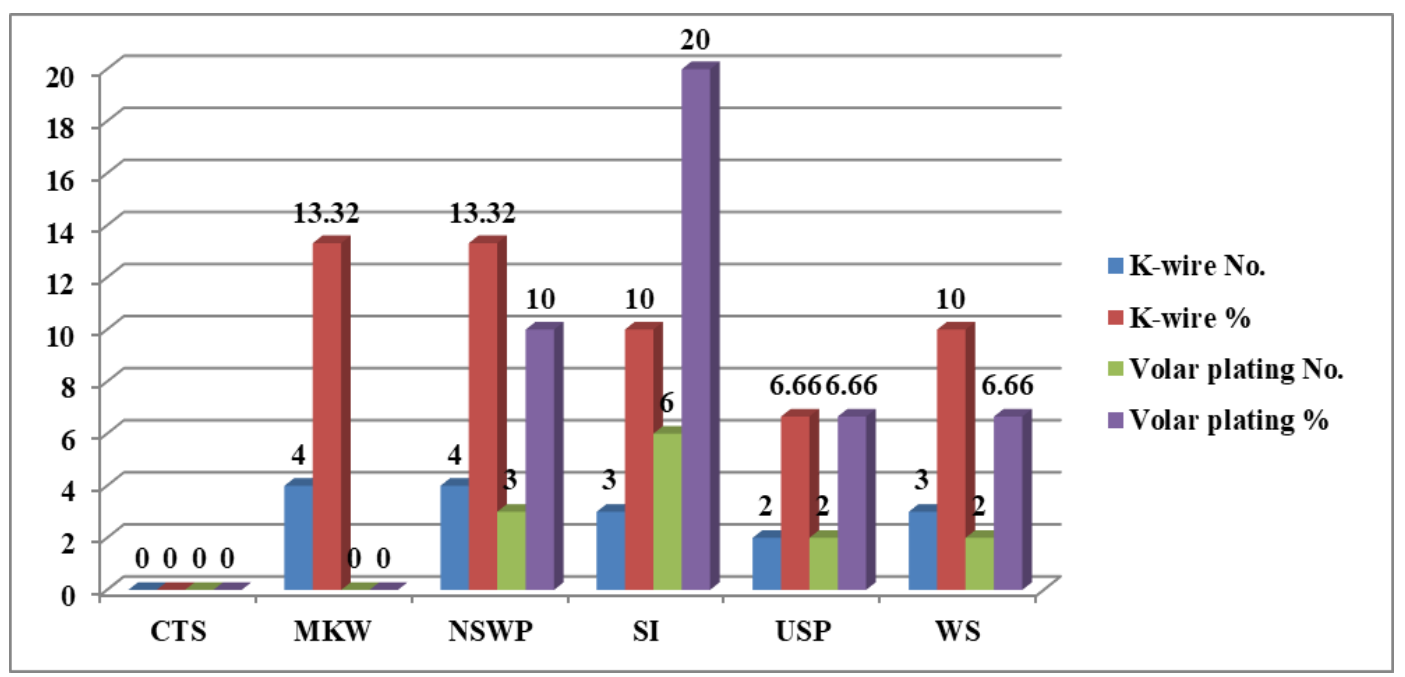

Graph 1: Distribution of case according to complication

Graph I shows that 3 patients had NSWP, 6 Patient had SI, 2 Patient had WS, 2 patient had USP in volar plate group. 4
Patient had MKW, 4 patients had NSWP, 2 patients had USP, 3 patients had SI, 3 patients had WS, in k wire group.

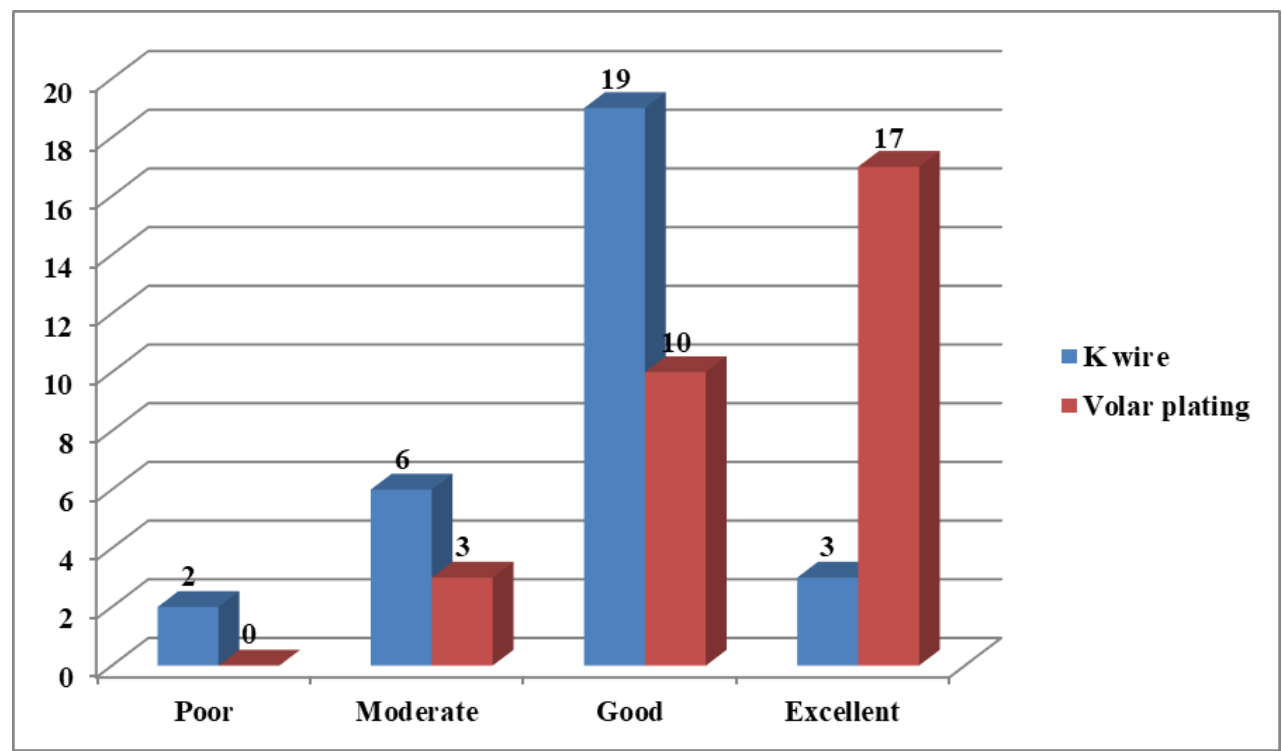

Graph 2: Distribution of case according to Outcome

Graph II shows that out of 30 patients $10 \%$ had excellent, $63.33 \%$ had good, $20 \%$ had moderate, $6.67 \%$ had poor results in $\mathrm{k}$ wire group. Out of 30 patients $56.67 \%$ had excellent,
$33.33 \%$ had good, $10 \%$ had moderate, $0 \%$ had poor results in volar plate group. 


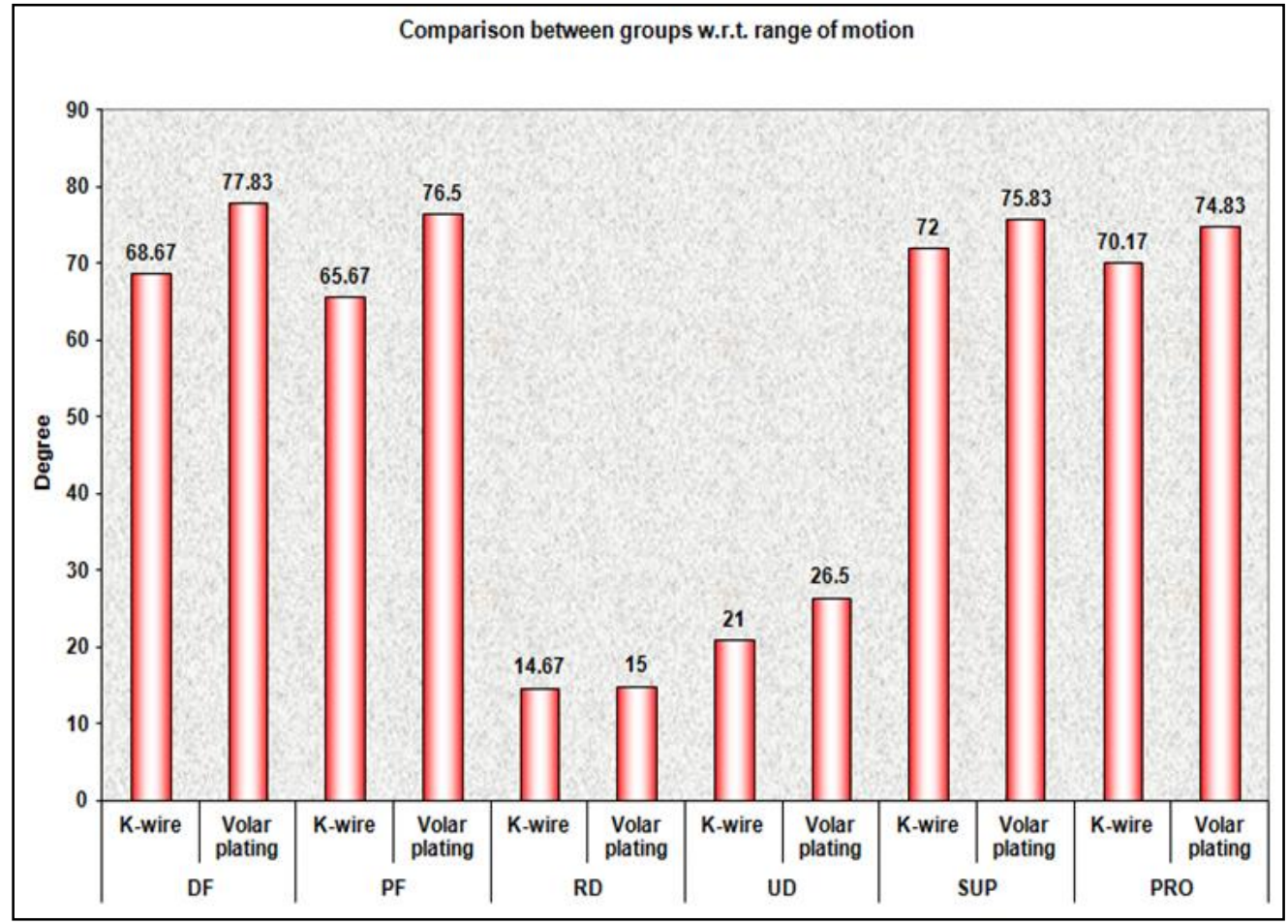

Graph 3: Distribution based on range of movement

Graph III shows that dorsiflexion was $77.83 \pm 6.65 \%$ in the VLP group and $68.67 \pm 9.55 \% \mathrm{KW}$ group respectively $(P<$ $.001)$; Palmer flexion was $76.50 \pm 6.97 \%$ and $65.67 \pm 9.98 \%$ respectively $(P<0.001)$; pronation was $74.83 \pm 7.82 \%$ and $70.17 \pm 7.93 \%$ respectively $(P=.025)$ and supination was
$75.83 \pm 5.10 \%$ and $72.00 \pm 6.64 \%$ respectively $(P<.001)$. Ulnar deviation was $26.50 \pm 3.97$ and $21.00 \pm 6.21$ (p less than.001). Radial deviation was $15.00 \pm 0.00$ and $14.67 \pm 1.27(\mathrm{p}=.161)$ respectively.

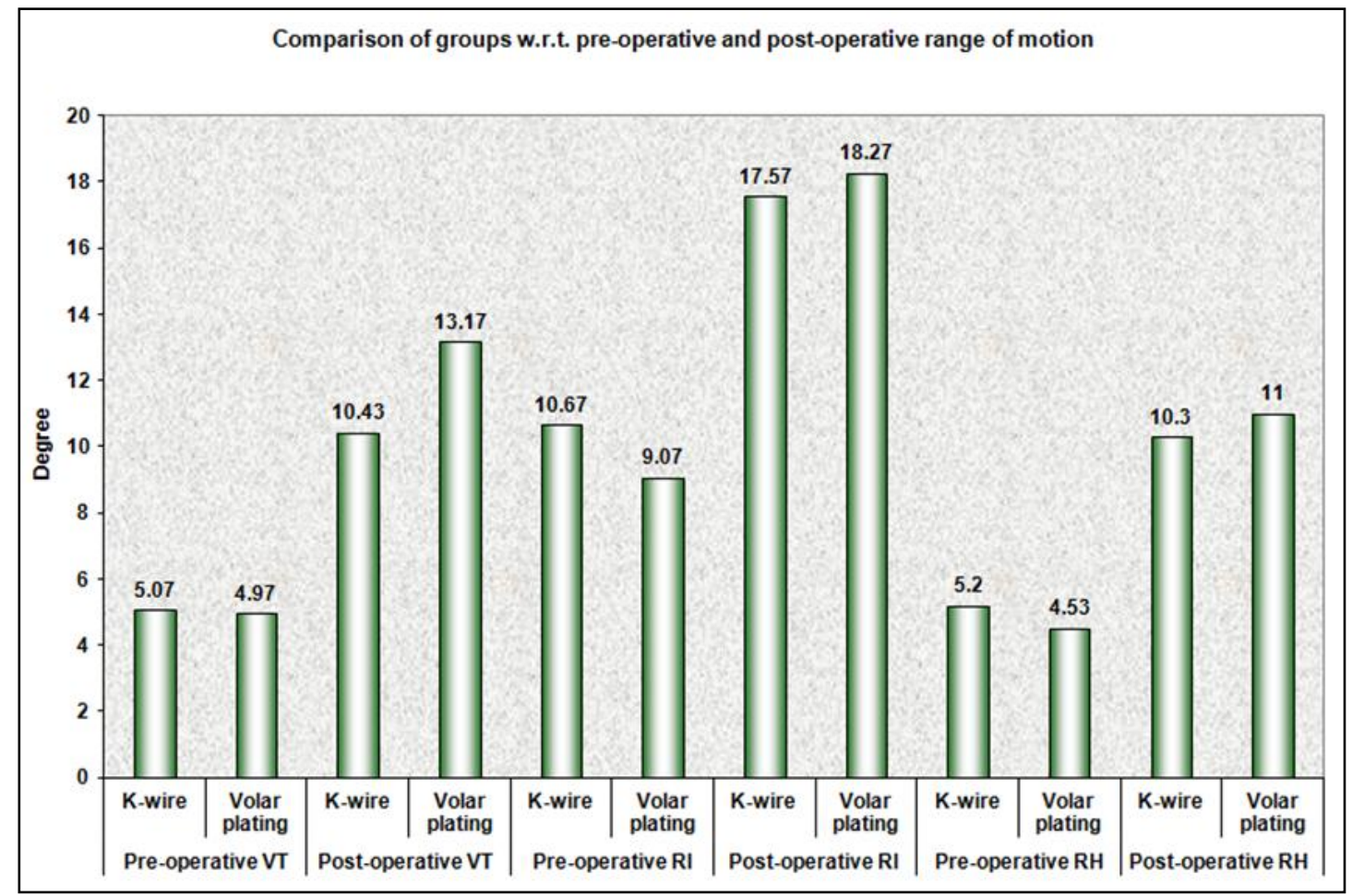

Graph 4: Distribution of case according to radiological variables

Graph IV shows that radiological variables were compared between $\mathrm{k}$ wire and volar plate group. Above table shows mean value of volar tilt (VT) at union in $\mathrm{k}$ wire group $10.43 \pm 2.06$ and mean value of VT at union in volar plate 13.17 \pm 2.77 . Mean value of Radial height $(\mathrm{RH})$ at union in $\mathrm{k}$ wire group $10.30 \pm 1.05$ and mean value of Radial height $(\mathrm{RH})$ at union in volar plate $11.00 \pm 0.83$ indicating volar plate have superior radiological outcome in comparison to $\mathrm{k}$ wire.

Table 5: Distribution of case according to DASH Score

\begin{tabular}{|c|c|c|c|c|}
\hline Group & N & Mean & Std. Deviation & 'p' Value* \\
\hline K-wire & 30 & 33.47 & 5.26 & \multirow{2}{*}{$<0.001$} \\
\cline { 1 - 4 } Volar plating & 30 & 28.03 & 5.19 & \\
\hline
\end{tabular}


Table $\mathrm{V}$ shows that mean DASH score in $\mathrm{K}$-wire fixation group is $33.47 \pm 5.26$ and mean DASH score Volar plate group came out $28.03 \pm 5.19$, indicating Volar plate group has better functional outcome in compare to $\mathrm{K}$ wire fixation group and it is statistically significant. ( $\mathrm{P}$ value $<0.05$ ).

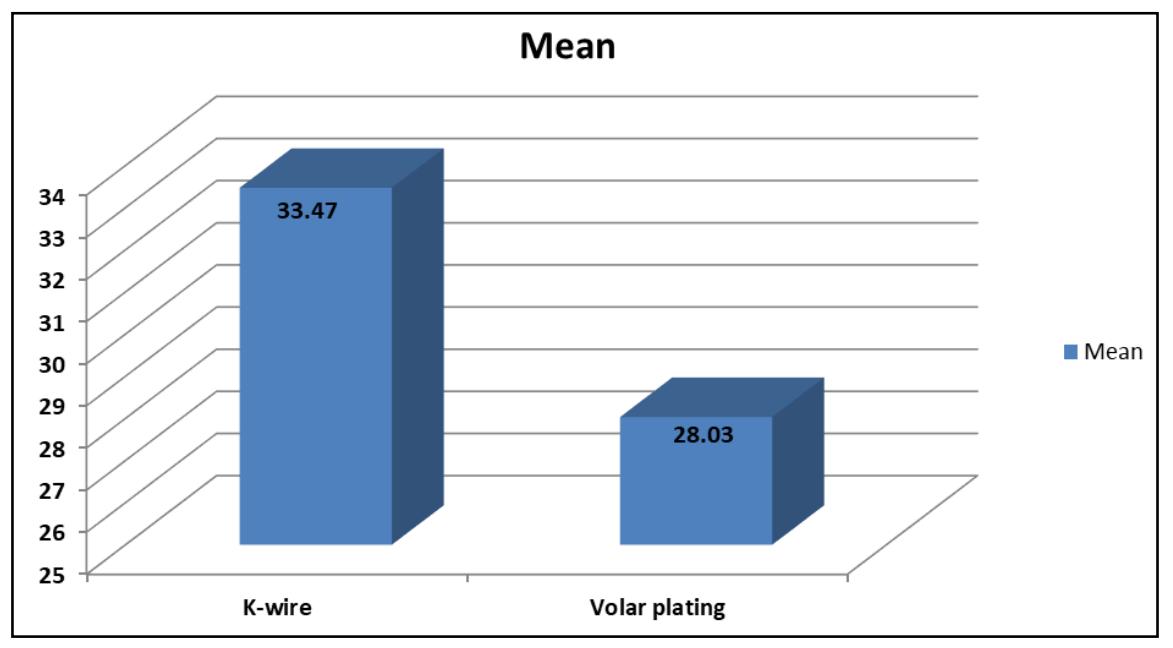

Graph 5: Distribution of case according to DASH Score

Graph V shows that mean DASH score in K-wire fixation group is 33.47 \pm 5.26 and mean DASH score Volar plate group came out $28.03 \pm 5.19$, indicating Volar plate group has better functional outcome in compare to $\mathrm{K}$ wire fixation group and it is statistically significant ( $\mathrm{P}$ value $<0.05$ ).

\section{Discussion}

Distal radius fractures are extremely common injuries and tend to occur in a bimodal age distribution. They are seen most frequently in young adults and again later in life in elderly, osteopenic women. These fractures are frequently articular injuries resulting in disruption of both the radiocarpal and distal radio ulnar joints. Most distal radius fractures are low-energy fractures, the result of a fall, and may be treated nonoperatively with some form of closed immobilization. High-energy distal radius fractures are more common in younger adults ${ }^{[7]}$.

A percentage of some of the comminuted, osteoporotic lowenergy fractures may be unstable injuries that require operative stabilization. The need for operative fixation of distal radius fractures in the elderly is becoming more common as the life expectancy in society increases and the elderly population stays more active and physiologically healthier ${ }^{[8]}$.

Handoll et al. ${ }^{[9]}$ compared a volar locking plate to an external fixator in treating unstable distal radius fractures. They concluded that the use of a volar fixed-angle implant resulted in stable fixation of the distal articular fragments, allowing early postsurgical wrist motion. The PRWE and DASH scores in the volar plating group were better than those seen in the external fixator group.

Handoll et al. ${ }^{[9]}$ concluded that the patients who underwent intrafocal pinning (IFP) experienced a significant loss of position, as measured by ulnar variance, in comparison to those who had volar plate fixation. Inaddition, patients who underwent volarlocking plate achieved an earlier recovery of post-operative range of motion and grip strength compared to IFP. In our Study DF, PF, UD, Supination and Pronation were found clinical significant in volar plate in compare to $\mathrm{K}$-wire with respective to their $\mathrm{P}$ Value. Our study matches with Nazar et al. ${ }^{[10]}$.

Belloti et al. ${ }^{[11]}$ prospectively randomised 45 patients to receive closed reduction and pin fixation or open reduction and volar plate fixation. Complex (C2 and C3) intra-articular fractures were excluded from the study group. The mean patient age was 51 years. They found that in the early postoperative period, those patients who were managed with plate fixation had a better range of motion, greater strength and lower DASH scores in comparison to those who had been managed with percutaneous pin fixation.

In our Study we found mean DASH score in K-wire fixation group 33.47 5.26 and mean DASH score Volar plate group came out 28.03 \pm 5.19 , indicating Volar plate group has better functional outcome in compare to $\mathrm{K}$ wire fixation group and it is statistically significant. Mean value of Radial height $(\mathrm{RH})$ at union in $\mathrm{k}$ wire group $10.30 \pm 1.5$ and mean value of Radial height $(\mathrm{RH})$ at union in volar plate $11.00 \pm 0.83$ indicating volar plate have superior radiological outcome in comparison to $\mathrm{k}$ wire. Our study matches with Ilyas et al. ${ }^{[12]}$.

In our study all 60 patient treated by randomised control trial in $\mathrm{k}$ wire and volar plate fixation union was occurred. Although mean value of union in $\mathrm{k}$ wire vs volar plate $(10.20 \pm 11.77$ vs $10.20 \pm 1.10)$ was not clinically significant.

Solgard et al. ${ }^{[13]}$ conducted a comparative study (prospective randomised trial) of unstable type A distal radius fractures in $\mathrm{k}$ wire vs volar plate group. The patient cohort included a wide range of ages (18-80 years) with a median age $>60$ years. Radiological assessment showed statistically better results at 6 weeks, 3 months and 6 months, respectively, for the plate group. The Gartland and Werley scores were significantly better in the plate group as were the DASH scores at 6 months' follow-up.

In our study $20 \%$ had SI in volat plate group and $10 \%$ had SI in $\mathrm{k}$ wire group. $10 \%$ had NSWP in volar plate group and $13.32 \%$ had NSWP in $\mathrm{k}$ wire group. Study conducted by Grewal et al $2.9 \%$ SI and .5\% NSWP in volar plate group, $8.0 \%$ SI and $.5 \%$ NSWP in k wire group ${ }^{[14]}$. The result of present systemic review confirmed some strength of volar plate. We found better outcomes for patient undergoing open reduction and plate fixation in term of DASH score and radiological outcomes quantitatively calculated from the data of studies.

\section{Conclusion}

Open reduction and internal fixation with a volar locking plate and closed reduction with percutaneous Kirschner wire 
fixation provide comparable excellent clinical and radiographic results in patients with distal radial fractures. At 12 weeks from the procedure, clinical results seem to favour patients treated with plating. The overall results of this review demonstrate a superior radiological, functional outcome and superior DASH score in volar plate.

\section{PREOP X-RAY}

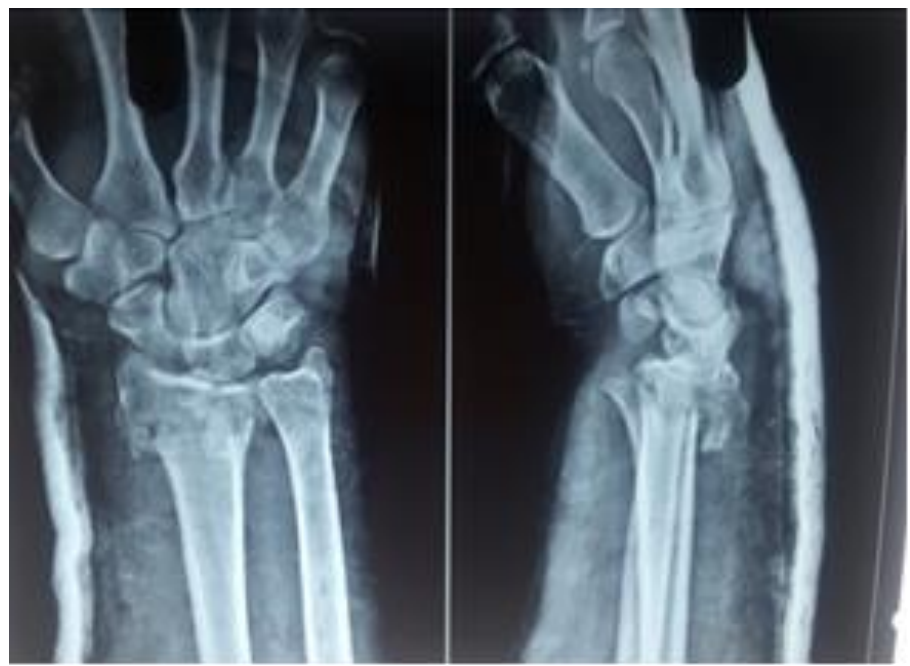

AP VIEW

LAT VIEW

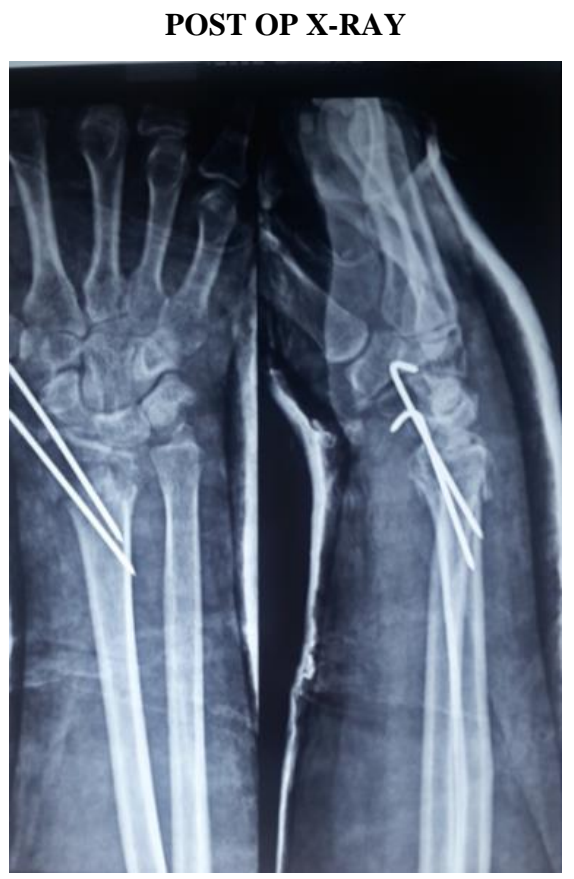

X-RAY AFTER UNION

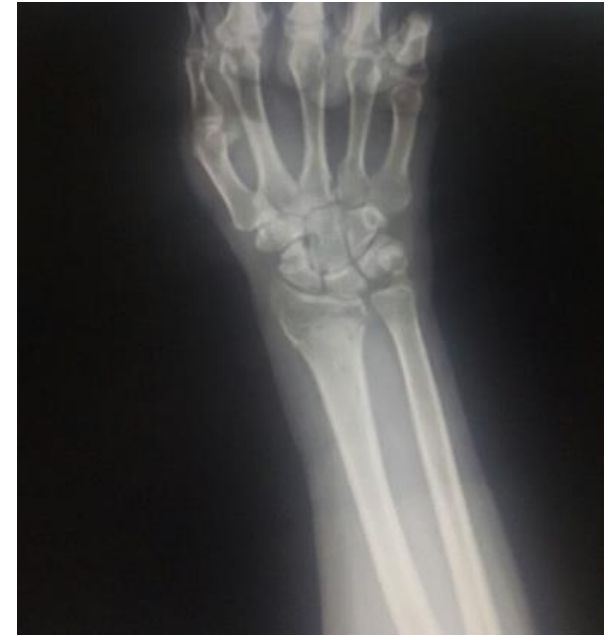

AP View

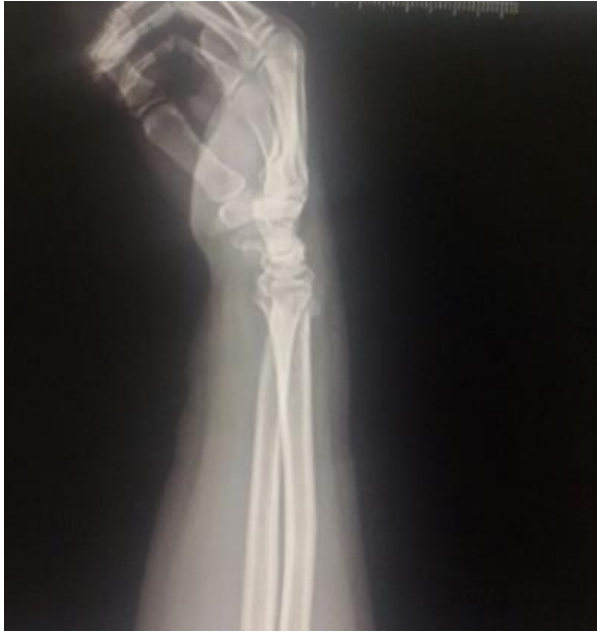

LAT View 
3 MONTH FOLLOW-UP
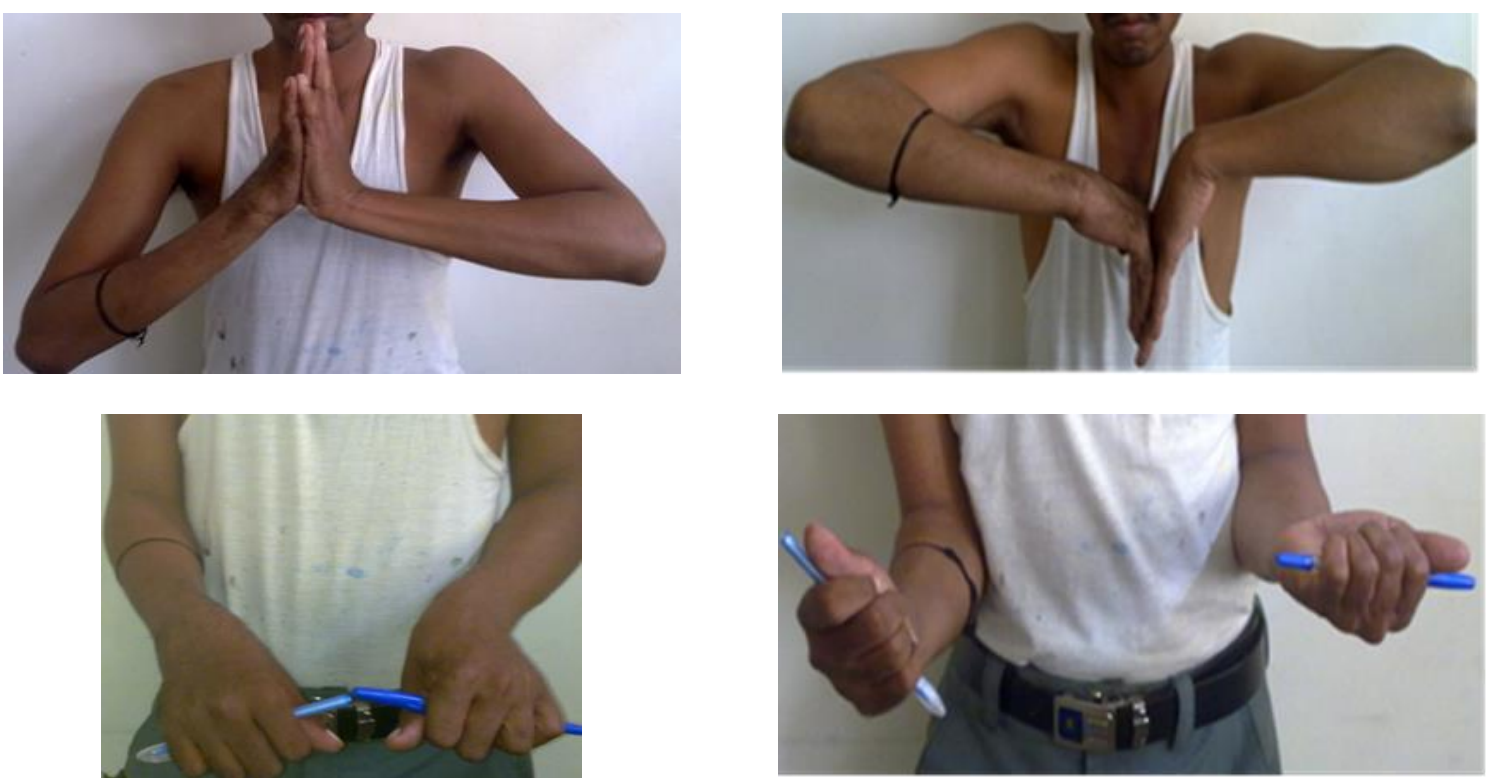

\section{LCP CASES}
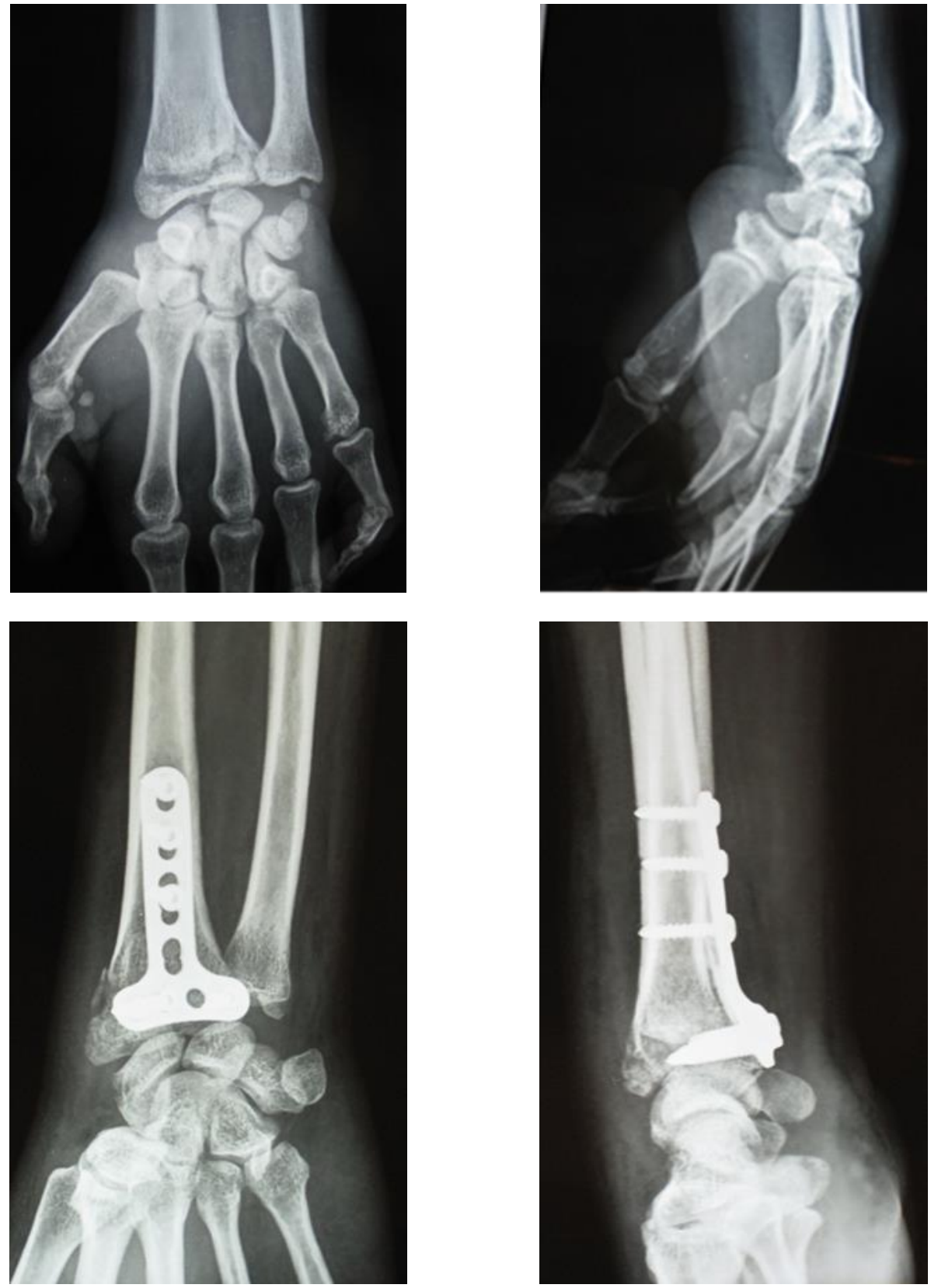

AP VIEW 


\section{X-RAY}
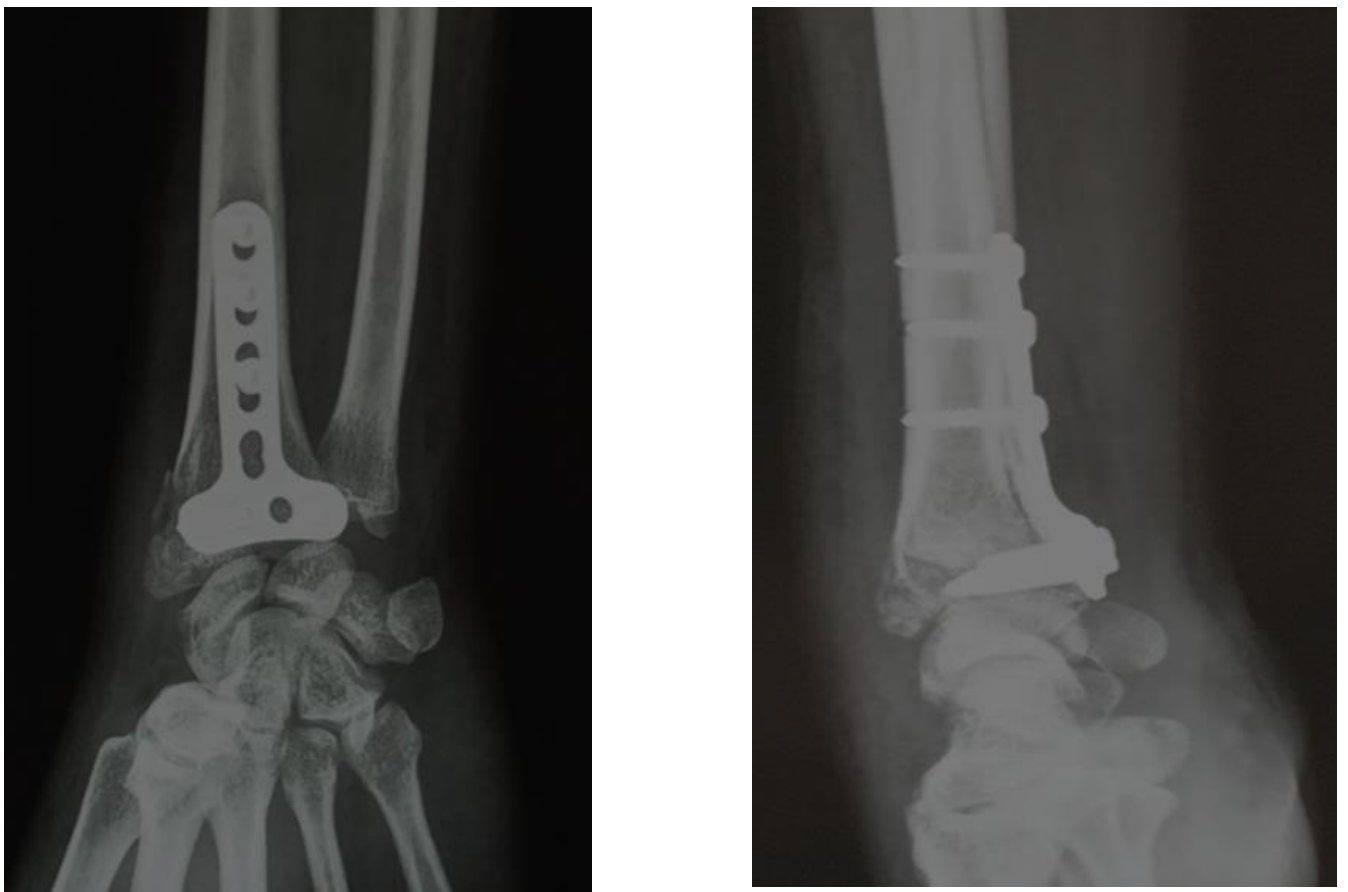

3 MONTHS FOLLOW -UP
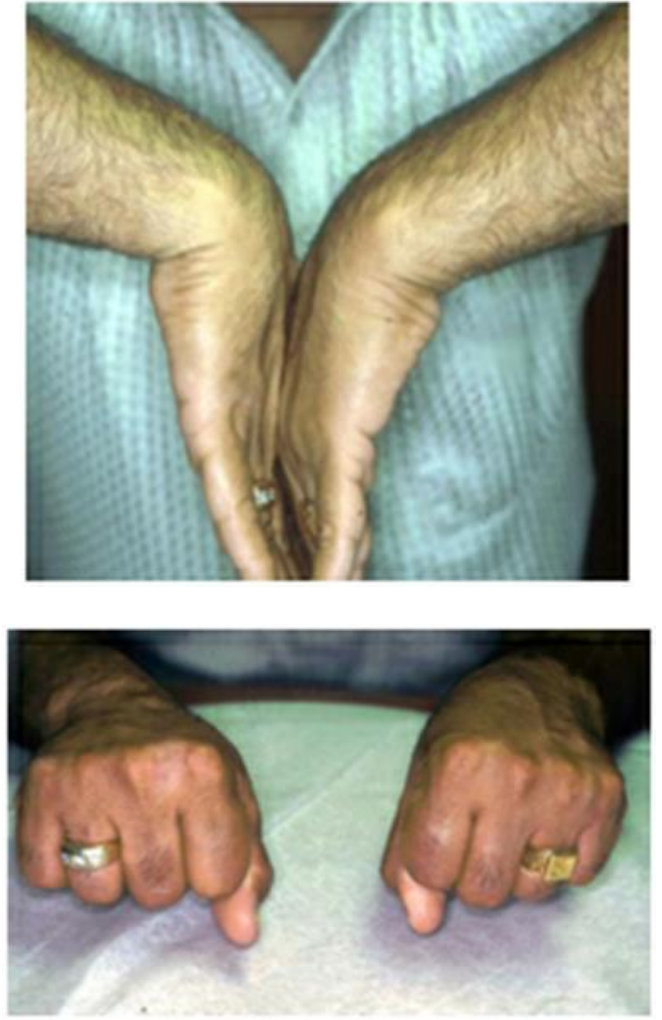

\section{References}

1. Harness NG, Meals RA. The history of fracture fixation of the hand and wrist. Clin Orthop Relat Res. 2006; 445:19-29.

2. Chen NC, Jupiter JB. Management of distal radial fractures. J Bone Joint Surg Am. 2007; 89(9):2051-62.

3. Wigg AE, Hearn TC, McCaul KA, Anderton SM, Wells VM, Krishnan J. Number, incidence, and projections of distal forearm fractures admitted to hospital in Australia. J Trauma. 2003; 55(1):87-93.

4. Handoll HH, Madhok R. Conservative interventions for treating distal radial fractures in adults. Cochrane
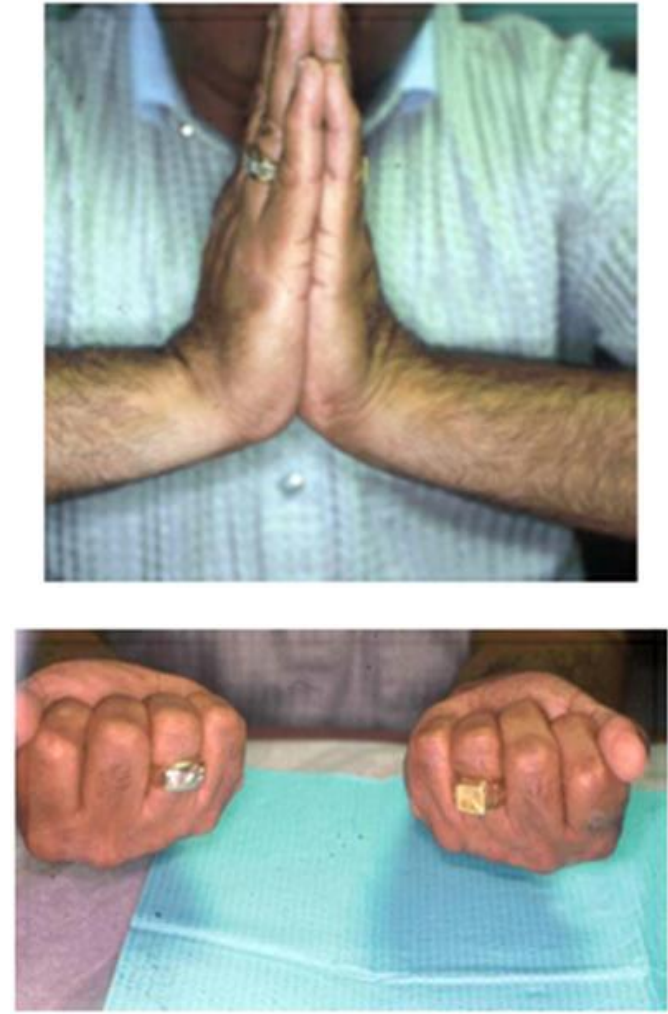

Database Syst Rev. 2002; (2):CD000314.

5. Hove LM, Fjeldsgaard K, Reitan R, Skjeie R, Sorensen FK. Fractures of the distal radius in a Norwegian city. Scand J Plast Reconstr Surg Hand Surg. 1995; 29(3):2637.

6. Brogren E, Petranek M, Atroshi I. Incidence and characteristics of distal radius fractures in a southern Swedish region. BMC Musculoskeletal Disord. 2007; 8:48.

7. Solgaard S, Petersen VS. Epidemiology of distal radius fractures. Acta Orthop Scand. 1985; 56(5):391-3.

8. Larsen CF, Lauritsen JM. Epidemiology of acute wrist 
injuries. Ugeskr Laeger. 1994; 156(19):2889-92.

9. Handoll HH, Vaghela MV, Madhok R. Percutaneous pinning for treating distal radial fractures in adults. Cochrane Database Syst Rev. 2007; (3):CD006080.

10. Nazar MA, Mansingh R, Bassi RS, Waseem M. Is there a Consensus in the Management of Distal Radial Fractures? Open Orthop J. 2009; 3:96-9.

11. Belloti JC, Santos JB, Atallah AN, Albertoni WM, Faloppa F. Fractures of the distal radius (Colles' fracture). Sao Paulo Med J. 2007; 125(3):132-8.

12. Ilyas AM, Jupiter JB. Distal radius fractures-classification of treatment and indications for surgery. Orthop Clin North Am. 2007; 38(2):167-73, v.

13. Solgaard S. Distal radius fractures. Classification, function and recommendations to treatment, 1992.

14. Grewal R, MacDermid JC, Pope J, Chesworth BM. Baseline predictors of pain and disability one year following extra-articular distal radius fractures. Hand. 2007; 2(3):104-11. 